\title{
Violência e socioeducação: uma interpelação ética a partir de contribuições da Justiça Restaurativa
}

\author{
Beatriz Aguinsky \\ Pontifícia Universidade Católica do Rio Grande do Sul (PUCRS)
}

\section{Lúcia Capitão}

Fundação de Atendimento Sócio-Educativo do Estado do Rio Grande do Sul (FASE/RS)

Violência e socioeducação: uma interpelação ética a partir de contribuições da Justiça Restaurativa Resumo: O presente trabalho debruça-se sobre a violência na contemporaneidade e a construção social do preconceito em relação à juventude em conflito com a lei. Desvela-se a socioeducação privativa de liberdade em suas premissas punitivas e tutelares que produzem um sistema de frágil resolutividade do atendimento. A proposta da Justiça Restaurativa é apresentada como uma possibilidade de avanço naquilo que preconiza o Estatuto da Criança e do Adolescente (ECA), por instituir práticas socioeducativas democráticas articuladas à rede de atendimento das políticas públicas da infância e juventude, oportunizando assim co-responsabilidades nas intervenções institucionais, na perspectiva de um Sistema de Garantia de Direitos para adolescentes privados de liberdade.

Palavras-chave: violência, socioeducação, Justiça Restaurativa.

Violence and Socioeducation: an Ethical Inquiry Based on the Contributions of Restorative Justice Abstract: This study analyzes contemporary violence and the social construction of prejudice in relation to youth in conflict with the law. It exposes socio-education deprived of liberty in its punitive and custodial premises that produce a system with a weak capacity to fulfill its service. The Restorative Justice proposal is presented as a possibility to advance the Statute of the Child and Adolescent by instituting democratic socio-educational practices within the service network of public policies for children and youth, establishing co-responsibilities in institutional interventions, from the perspective of a System of Guarantee of Rights for youths deprived of liberty. Key words: violence, socioeducation, Restorative Justice. 


\section{Introdução}

Os 18 anos do Estatuto da Criança e do Adolescente (ECA) desafiam a construção de novos significados para velhas questões: como fazer prevalecer uma cultura de direitos humanos nas respostas da esfera pública às violências em que adolescentes tomam parte? O convite à reflexão apresentado neste artigo interpela eticamente estas respostas, considerando suas expressões particulares em termos de práticas socioeducativas, no âmbito da privação de liberdade. Apesar dos avanços civilizatórios representados pelos marcos referenciais do ECA para as políticas públicas no âmbito da socioeducação, pode-se dizer que ainda nos encontramos no meio do caminho da obtenção de respostas seguras. Persiste o desafio de construção de práticas institucionais e sociais que superem a cultura punitiva que, longamente, vem servindo de solo histórico para as 'formas de ser' das medidas socioeducativas. Os operadores das políticas públicas para a juventude em conflito com a lei confrontam-se cotidianamente com os apelos conservadores: a naturalização da cultura da violência especialmente a violência institucional como forma inevitável de resposta a violências que se refratam nas trajetórias de vida desses adolescentes.

Nesse quadro, fazem-se urgentes as contribuições das diversas áreas do conhecimento e das mais variadas práticas sociais que possam agregar valores éticos e vigor político na fundamentação do significado social das respostas da esfera pública aos crimes praticados pela juventude brasileira, reafirmando a perspectiva de garantia de direitos humanos da qual o ECA é herdeiro. Uma nova concepção de justiça - a Justiça Restaurativa - definida pelo Conselho Econômico e Social da ONU (2002) como "[...] qualquer processo no qual a vítima e o ofensor e, quando apropriado, quaisquer outros indivíduos ou membros da comunidade afetados por um crime, participam ativamente na resolução das questões oriundas do crime, geralmente com a ajuda de um facilitador", é discutida como uma possível alternativa a essa situação de barbárie. A Justiça Restaurativa, através da afirmação de valores como responsabilização, inclusão, participação e diálogo, pode corresponder a anseios civilizatórios inadiáveis nos tempos presentes em que a violência teima em se impor como forma natural de sociabilidade.

\section{A violência e o preconceito social em relação à juventude em conflito com a lei}

Com o adensamento das desigualdades e de suas múltiplas repercussões, dentre elas a violência, ganham terreno os apelos do senso comum, na busca de respostas simplistas para fenômenos complexos que emergem como caixa de ressonância da barbárie que se naturaliza no cotidiano das relações sociais. A veemência dos recentes clamores pela redução da idade penal coloca em risco, como nunca, a conquista civilizatória representada pelos marcos do ECA no reconhecimento dos adolescentes em conflito com a lei como sujeitos de direitos plenos e em situação peculiar: sujeitos em desenvolvimento.

No entanto, esta situação peculiar, no âmbito da intervenção do Estado e das políticas públicas, tende a se tornar visível apenas na esfera da criminalização. Nessa ótica, o poder punitivo de uma sociedade institucionaliza o poder (Estado), selecionando algumas pessoas que estarão sujeitas a sua coação e à imposição de penas. Tal seleção penalizante, que corresponde à criminalização, efetiva-se por vários segmentos que compõem o sistema penal. Através dela, há um acesso negativo dos sujeitos à comunicação social, contribuindo para a criação de estereótipos e preconceitos "[...] o que resulta fixar uma imagem pública do delinqüente com componentes de classe social, étnicos, etários, de gênero e estéticos" (ZAFFARONI et al., 2003, p. 46).

$\mathrm{Na}$ medida em que o tema da violência vem ganhando cada vez mais terreno em distintos espaços e discussões, não se pode desconhecer o quanto é conservador o discurso hoje prevalente de delegação (sobre alguns grupos seletivamente identificados) da principal responsabilidade pela criminalidade, o que vem reforçar estigmas e avalizar práticas legais de violência para combater a violência ilegal. Essa tendência é tematizada, também, por Caldeira (2008, p. 43) ao afirmar que "A fala do crime é produtiva, mas o que ela ajuda a produzir é segregação (social e espacial), além de abusos por parte das instituições da ordem, contestação dos direitos da cidadania e, especialmente, a própria violência."

Além disso, o preconceito no discurso socialmente produzido sobre o crime remete a contradições históricas que materializam tensões entre os avanços das conquistas democráticas no país e sua negação para alguns segmentos sociais. São tensões que fortalecem práticas de violência policial e de privatização das respostas sociais ao crime, associadas ao aumento de grades, muros e barreiras nas relações sociais, repercutindo na supressão de espaços de convivência democrática na esfera pública. Ainda, segundo Caldeira (2008, p. 45), “[...] a violência e o crime não existem isoladamente na sociedade brasileira, mas sim num tenso diálogo com a consolidação democrática." Este é o cenário que desafia a democratização das medidas socioeducativas, invadidas historicamente pelos efeitos inerciais da cultura punitiva e de vingança, embalando as respostas da esfera pública nas violências em que a juventude toma parte. 


\section{A privação de liberdade e a socioeducação: premissas punitivas e tutelares em xeque}

O ECA colocou em xeque a histórica dicotomia de pressupostos retributivos e tutelares em torno dos quais, longamente, organizaram-se as disputas teóricas, ideológicas e políticas sobre socioeducação. As transformações introduzidas pelo Estatuto são sintetizadas por uma idéia de justiça convergente com um modelo de justiça e garantias para adolescentes em conflito com a lei. Estas transformações remetem a processos históricos contraditórios em que tutela e coação sempre estiveram presentes:

Para aqueles que foram conscientes da verdadeira profundidade e natureza das transformações, era claro que não se tratava somente de erradicar de forma definitiva as 'más' práticas autoritárias, repressivas e incriminadoras da pobreza. Tratava-se (e trata-se ainda), sobretudo, de eliminar as 'boas' práticas 'tutelares e compassivas'. Partia-se aqui da constatação, lamentavelmente confirmada reiteradamente pela história, de que as piores atrocidades contra a infância se cometeram (e se cometem ainda hoje) muito mais em nome do amor e da compaixão que em nome da própria repressão. Tratavase (e trata-se ainda) de substituir a 'má', porém também 'boa' vontade, nada mais - mas também nada menos - pela justiça. No amor não há limites, na justiça sim. Por isso, nada contra o amor quando o mesmo se apresenta como um complemento da justiça. Pelo contrário, tudo contra o 'amor' quando se apresenta como um substituto cínico ou ingênuo da justiça (MENDEZ, 2001, online, grifos do autor).

Os traços punitivos e assistencialistas das práticas institucionais permanecem presentes na contemporaneidade. No entanto, desde a promulgação do ECA, a privação de liberdade na socioeducação vem se confrontando com as necessidades de construção de respostas aos impasses, ainda não superados nas práticas institucionais que se estruturam na base das políticas públicas voltadas aos adolescentes em conflito com a lei. As formas cotidianas de ser dessas práticas testemunham em favor de estratégias sociopedagógicas que pretendem responsabilizar adolescentes infratores através de sua culpabilização individual. Por outro lado, impõem-lhes, sofrimento e isolamento, através de formas assistencialistas de atenção que se atualizam na produção social da passividade e desresponsabilização. São lógicas que convivem na socioeducação e que, contraditoriamente, sustentam-se tanto por um ideal retributivo quanto tutelar, ambos antinômicos ao espírito democrático do ECA:

[...] o modelo do ECA demonstra que é possível e necessário superar tanto a visão pseudo-progres- sista e falsamente compassiva, de um paternalismo ingênuo de caráter 'tutelar', quanto à visão retrógrada de um retribucionismo hipócrita de mero caráter penal repressivo (MENDEZ, 2001, online, grifo do autor).

Oscilando entre a face maquiada da mera punição, e a face humanizada de cunho terapêutico-tutelar, assiste-se à convivência, na cena contemporânea, de mecanismos de intervenção que terminam por reproduzir duas nefastas práticas sociais: a violência como resposta à violência; ou, seu anverso, a tutela domesticadora de vontades, corpos e mentes, embalada por mecanismos assistencialistas, associados pelo senso comum à permissividade. Nesse espírito, acalentam-se as gritas pela redução da idade penal e também os sentimentos de insegurança das vítimas de violência que terminam por rivalizar com a lei, no caso, com o ECA.

As práticas focalizadas na mera punição, ou que não distinguem responsabilização e tratamento, são alvo de críticas severas pela argumentação fundamentada nos direitos humanos, por não respeitarem a autonomia e a condição de sujeito de direitos do adolescente, submetido, assim, à posição de sujeito passivo que precisa de tratamento, de quem é subtraída a experiência social com a violência, num conjunto de estratégias de resistência a desigualdades que adensam em seu modo e condição de vida.

Admitir o quanto o mero contato com o sistema de justiça na socioeducação convoca o reconhecimento do potencial de violência, que inerentemente carrega, parece o ponto de partida para assumir-se a tarefa histórica dos defensores dos direitos humanos neste campo: a redução do dano, ou melhor, a luta pela redução das violências nas respostas públicas às violências de que a juventude toma parte e que terminam por chegar a este sistema:

\section{[...] o ingresso no Sistema de Justiça passou a ser reconhecido como inerentemente violador, seja no sentido teórico de que é pela coerção judicial que se materializa o princípio do monopólio estatal da violência, seja pelo sentido prático de que as es- truturas institucionais e seus mecanismos buro- cráticos tendem a suprimir a individualidade do sujeito e a submetê-lo a uma ampla gama de vio- lências institucionais (BRANCHER; AGUINSKY, 2006a, p. 477-478).}

A violência antes referida tem base na cultura da punição e da tutela, refratando significados conservadores que habitam nos processos identitários que, cotidianamente, vão se forjando sobre a socioeducação e seu métier. Isso converge em práticas sociais, institucionais e profissionais, não raro antinômicas a uma cultura de 
direitos humanos, nas formas de atendimento, no âmbito da privação de liberdade.

\section{A frágil resolutividade do atendimento socio- educativo: solo propício à cultura punitiva}

Na tensão entre os significados conservadores que seguem operando através das premissas punitivo-tutelares na socioeducação, o que está em xeque é a da falta de sentidos na construção das próprias medidas socioeducativas. As pesquisas qualitativas no âmbito da privação de liberdade têm indicado que "[...] não é a prisão que proporcionará a mudança tão sonhada pelo conjunto da sociedade, porque representa uma punição vazia de sentido" (SCHMIDT, 2007, p. 64).

Nesta falta de sentidos, a vivência das medidas socioeducativas, especialmente as privativas de liberdade, hoje tão reclamadas como 'a tabula rasa de salvação' para a violência na sociedade brasileira, tende a repercutir em experiências sociais de alienação, por vezes de aprendizado da hipocrisia social, que antes produzem desresponsabilização:

[...] ao não assegurar direitos, tanto no meio fechado quanto no aberto, o Sistema acaba por centrarse na face punitiva, cumprindo o papel que sempre teve. Ao deixar de dotar as medidas de sentido, confirma seu vazio valorativo e não produz novos efeitos sobre a subjetividade do adolescente, bem como quanto às suas condições concretas de vida. A inovação do paradigma da garantia de direitos impõe a subversão dessa ótica. Desafia a pensar outras práticas que articulem responsabilização com cidadania (TEJADAS, 2005, p. 286-287).

A desresponsabilização mencionada refere-se ao empobrecimento ético da socioeducação que, no cotidiano, materializa-se na ausência de sentido pedagógico em favor de um preponderante sentido punitivo. Nessa esteira, vale afirmar que o atendimento socioeducativo vem-se mostrando eficiente naquilo que concerne à vigilância da privação de liberdade, ou seja, a manter adolescentes autores de ato infracional sob rígida vigilância e segregação da sociedade. Contudo, no que diz respeito à efetividade da medida socioeducativa, vislumbra-se certo descompasso entre o que o sistema de garantias de direitos propõe e aquilo que é alcançado no interior das instituições privativas de liberdade. A finalidade da medida, como claramente destaca o Sistema Nacional de Atendimento Socioeducativo (Sinase) ${ }^{1}$, orienta-se não apenas por uma dimensão sancionatória, mas conforma-se, sobretudo, por uma dimensão ético-pedagógica. Essa orientação ético-pedagógica deixa muito a desejar, pois as unidades de internação não garantem, no decorrer da retenção, uma efetiva proposta pedagógica, fundamentada na autonomia, no protagonismo, no respeito às diversidades, às dificuldades e potencialidades do grupo familiar desses adolescentes. Com o que visaria à co-responsabilização não só pelo retorno ao convívio familiar e comunitário, mas também para a garantia da dignidade e segurança dos jovens nessa situação.

As fragilidades do conteúdo ético-pedagógico das medidas repercutem em uma fragilização de sua resolutividade. Isso contribui para que sua eficácia seja questionada, especialmente em razão de indicadores de reincidência (hoje pouco confiáveis pela falta de pesquisas científicas com bases teóricas e metodológicas sólidas sobre o tema). Além da tragédia cotidiana de vidas de jovens ceifadas diante do confronto postergado com grupos rivais, muitas vezes gerado pelo próprio ato infracional, ou por vivências relacionadas ao tráfico de drogas. Outros, ainda, terminam sendo conduzidos à justiça penal adulta, com todas as conseqüências gravosas para a dignidade humana associadas ao sistema prisional. Esta realidade impõe enormes desafios na qualificação do sistema socioeducativo, o que já vem sendo desenvolvido em algumas experiências exitosas no país:

Os desafios enfrentados consolidam um caminho de aprendizagem em que a construção de alternativas para as dificuldades encontradas questiona os usuais lugares e formas de constituição dos saberes, poderes e fazeres que convergem a este campo. A novidade que ora se apresenta, em termos da gestão e execução das medidas socioeducativas, radica no enfrentamento do que é simples, mas usualmente impensável: as práticas institucionais, sociais e profissionais, que materializam o espírito do Estatuto, não poderão alterar-se por prescrição (BRANCHER;AGUINSKY, 2006a, p. 470).

A qualificação do sistema socioeducativo exige responsabilidade compartilhada e aprendizado coletivo. Por essa razão, não se pode ponderar sobre resolutividade do atendimento socioeducativo a partir dele mesmo. Ou seja, esse desafio é pertinente à co-responsabilidade no âmbito do conjunto das políticas públicas para a infância e juventude. Adolescentes com deficiente acesso às políticas públicas da educação, cultura, esporte, lazer, profissionalização e trabalho, recebem apoio para a sobrevivência do tráfico de drogas e da criminalidade.

Tanto o texto legal do Estatuto quanto - e sobretudo - seus comentários pelos doutrinadores, são permeados pela idéia de que a efetividade dos direitos ali dispostos dependem da absorção de uma ética de co-responsabilidade, capaz de respeitar a realidade complexa do fenômeno social subjacente à operação da incidência da norma jurídica, para 
tanto considerando que a solução de cada caso concreto tem por pressuposto, no campo da apreensão da respectiva realidade, uma abordagem interdisciplinar, e, no campo das práticas intervenientes, de uma ação necessariamente interinstitucional e articulada (BRANCHER; AGUINSKY, 2006a, p. 472).

Há urgência de uma ética de co-responsabilidade e de busca incansável da intersetorialidade das políticas públicas para o enfrentamento dos desafios da ampliação da cidadania da juventude brasileira, especialmente daquela submetida à seletividade punitiva do Estado. Nessa direção, é relevante o observado pelo presidente Luiz Inácio Lula da Silva, no discurso proferido na VII Conferência Nacional dos Direitos da Criança e do Adolescente, de dezembro de 2007. Quando o presidente fez referência aos dados apresentados pelo Instituto de Pesquisa Econômica Aplicada (IPEA), destacou que dos 9.500 adolescentes que cumpriram medidas de internação no ano de 2002, 97\% eram afro-descedentes, 90\% não haviam concluído o ensino fundamental, 51\% não fre-

\section{Aqueles que entendem que}

punir é sinônimo de educar não hesitam em, rapidamente, atribuir ao adolescente, autor de ato infracional, a principal responsabilidade de toda a violência instalada no cotidiano

social. qüentavam escola, $66 \%$ dos jovens internados viviam em famílias de renda mensal de até dois salários mínimos e $12,7 \%$ viviam em famílias que não possuíam qualquer renda mensal. Esses dados convocam a todos, Estado e sociedade civil, à produção de novos sentidos para a socioeducação, articulando-os às demais políticas públicas.

\section{0 meio do caminho: entre a possibilidade de avançar e os riscos regressivos}

A naturalização da barbárie e a reprodução social das violências parecem ser o signo mais persistente da contemporaneidade. O adensamento das desigualdades sociais, que se perpetua pela redução do estado social, e os clamores de ampliação de um estado penal tendem a refratar-se em formas de respostas da esfera pública através da segregação e da punição (WACQUANT, 2001). A violência vem sendo enfrentada de forma violenta, sem, contudo, produzirem-se ações eficazes no sentido de reverter-se o quadro de desigualdade social do país. A negação da situação atual de desigualdade social, campo fértil da criminalização, aponta para um contexto em que a privação de liberdade se estende do jovem autor de ato infracional para aqueles que, de forma passiva ou ativa, compactuam com as desigualdades sociais e com o que dela resulta. Atrás das grades, seja das unidades de detenção ou das moradias, estão todos, colocando em xeque a própria vida.

O pensamento conservador, por sua vez, atualiza-se no campo das políticas públicas para os adoescentes vulneráveis penalmente. Aqueles que endem que punir é sinônimo de educar não hesitam em, rapidamente, atribuir ao adolescente, autor de ato infracional, a principal responsabilidade de toda a violencia instalada no cotidiano social. O conservadorismo, então, reivindica um espaço para a juventude atrás das grades do sistema penal adulto. Forças conservadoras da sociedade tentam provar que a redução da idade penal garante a diminuição da violência urbana. Esta lógica se relaciona ao sentimento de insegurança da população diante de ações ineficazes de combate à criminalidade. Contudo, condenar jovens de 16 e 17 anos não é indicativo de resolução do problema da criminalidade, pois a violência social não é fruto da juventude em conflito com a lei. Atribuir a um determinado segmento populacional a responsabilidade pela violência cria, no imaginário social, a idéia de isenção da responsabilidade coletiva na busca de alternativas para uma situação, já insustentável. O que se exige mesmo são ações de não-violência, de responsabilização compartilhada entre Estado e sociedade civil na constituição de uma nova esfera pública, alicerçada em uma ética orientada pela afirmação de direitos humanos para todos. Importante lembrar que muitos engrossam as filas da violência. São responsáveis tanto aqueles que se omitem diante da desigualdade social, como os que desfrutam de privilégios e só aumentam a invisibilidade social dos jovens, que estão num momento fundamental de afirmação e busca de reconhecimento.

É por isso que os 18 anos do ECA, comemorados em julho de 2008, apontam questionamentos na ordem de sua implantação e maturidade ao longo da sua trajetória. Ao observar a política pública socioeducativa, desvelam-se algumas situações cotidianas presentes na internação provisória, nas medidas de meio aberto e na execução da privação de liberdade, tanto na internação quanto na semiliberdade, que violam direitos humanos dos internados.

Em termos de internação provisória, (prevista no ECA para uma duração de, no máximo, 45 dias), vem 
ganhando terreno uma tendência do sistema de justiça de ampliar o tempo de privação de liberdade no período de definição de medida. Há adolescentes que permanecem por até quatro meses ${ }^{2}$ à espera de uma definição acerca da responsabilização penal sobre o ato infracional.

Quanto às medidas de meio aberto (liberdade assistida e prestação de serviços à comunidade), verifica-se que, em não sendo implantadas pelos municípios, tendem a transportar para a privação de liberdade casos de sua alçada.

Finalmente, quanto às medidas de privação de liberdade, tem-se, no âmbito da internação, a questão premente da superlotação que impede a garantia de direitos humanos dos adolescentes sob a responsabilidade do Estado. São violações de direitos que remetem a insuficiências que iniciam pelo espaço físico, passam pelo atendimento técnico, pelo deficiente acesso a recursos de higiene pessoal e coletiva, por escassas ofertas de atividades ocupacionais e profissionalizantes, chegando até um limitado acompanhamento ao grupo familiar, eventos que debilitam a possibilidade de uma ação pedagógica na socioeducação. Já no âmbito da semiliberdade, constata-se que, ao longo dos anos de vigência do ECA, vem ocorrendo uma incipiente integração da socioeducação com a comunidade e com as políticas públicas para a juventude. A tendência é de uma maior concentração de adolescentes em situação de privação de liberdade do que em semiliberdade, questionando, assim, a efetiva possibilidade da socioeducação sem tantas grades e muros.

A socioeducação é atravessada por todas estas questões que a colocam em xeque diante dos riscos de retrocesso em relação àquilo que o ECA preconiza, ou seja, uma educação sancionatória, de natureza interditória ao ato infracional, mas, acima de tudo, pedagógica. Considera-se, assim, que a socioeducação está, ainda, distante da democratização tão almejada para esse atendimento. Encontra-se no meio do caminho, na trilha da efetiva orientação ético-pedagógica, nas práticas de responsabilização juvenil pela prática de atos infracionais. A Justiça Restaurativa indica a possibilidade de avançar na qualificação do atendimento socioeducativo, apresentando pressupostos teóricometodológicos e éticos que questionam os paradigmas existentes. No seu bojo, erguem-se possibilidades de construção social de respostas, no âmbito das políticas públicas, que se materializem em práticas institucionais que concretizem o paradigma da garantia de direitos aos adolescentes, autores de ato infracional, em cumprimento de medida privativa de liberdade e, também, de alternativas para esta privação.

\section{A Justiça Restaurativa na socioeducação: uma possibilidade de progressão}

Os achados teóricos da Justiça Restaurativa se alinham com possibilidades de respostas humanizadoras às contradições entre punição e tratamento. A Justiça Restaurativa, ao invés de versar sobre transgressões e culpados, materializa possibilidades concretas de participação individual e social, democratização do atendimento, acesso a direitos, afirmação de igualdade em espaços de diálogo, em ambientes seguros e respeitosos, valorização das diferenças, através de processos sociopedagógicos que considerem os danos, os responsáveis pelos mesmos e os prejudicados pela infração.

Ao contrário da justiça tradicional, que se ocupa predominantemente da violação da norma de conduta em si, a Justiça Restaurativa valoriza a autonomia dos sujeitos e do o diálogo entre eles. Cria espaços protegidos para a autoexpressão e o protagonismo de cada um dos envolvidos e interessados - transgressor, vítima, familiares, comunidades - na busca de alternativas de responsabilização (MCCOULD; WATCHEL, 2003). Nessa perspectiva, pode-se contribuir para fortalecer o protagonismo dos sujeitos na construção de estratégias para restaurar laços de relacionamento e confiabilidade social rompidos pela infração. Enfatizando o reconhecimento dos direitos humanos de todos, e a reparação das conseqüências de atos lesivos que decorrem de infrações à lei penal, humaniza a consideração das relações atingidas pela infração, de forma a gerar maior coesão social na geração de compromissos coletivos com um futuro melhor. Tal projeção só se constitui com responsabilidades partilhadas (envolvendo atores do ato infracional, familiares, comunidade, vítimas, operadores da rede, entre outros), sem se descuidar da responsabilização do autor do ato infracional 
e da possibilidade de colocar em perspectiva um projeto de convivência social e comunitária, tão liberto quanto possível das armadilhas utilitárias. Tais armadilhas estão presas a ciclos de reprodução de confrontos que se perpetuam em relações autoconsumptivas entre violências e atendimento de necessidades sociais e individuais, como se uma implicasse, forçosamente, a outra.

Através das práticas de Justiça Restaurativa, o foco muda do culpado para as conseqüências da infração. Para haver um ambiente de respeito com a dignidade - capacidade e autonomia - do adolescente infrator, é fundamental que a vítima seja atentamente incluída no processo. Quanto à participação da comunidade nas práticas restaurativas, torna-se relevante a mobilização de o máximo de pessoas que se mostrem relacionadas às partes envolvidas no conflito. Ou ainda, que possam contribuir em sua solução, abrindo espaço à participação tanto de familiares, amigos ou pessoas próximas do infrator ou da vítima, como de representantes da comunidade atingida direta ou indiretamente pelas conseqüências da infração.

A mudança de paradigma em relação à privação de liberdade pode permitir que essa se constitua, também, em espaço de crítica do próprio atendimento socioeducativo, possibilitando mudanças e adequações na qualidade dos serviços prestados com a participação do adolescente. Iniciativas de Justiça Restaurativa na privação de liberdade estão em prospecção em Porto Alegre, Rio Grande do Sul, desde 2005. São iniciativas que instituem uma nova proposta de atendimento e que foram analisadas em pesquisa recente nesse município, envolvendo adolescentes internados, familiares e rede de atendimento das políticas públicas. A pesquisa observa que:

A Justiça Restaurativa na privação de liberdade de adolescentes autores de ato infracional desacomoda o instituído. Reorganiza os lugares pré-estabelecidos dos adolescentes, familiares e profissionais tanto da FASE quanto da rede de atendimento. O lugar há muito tempo ocupado pelos profissionais, um lugar prescritivo, vertical, hierárquico, pode ser desocupado. A noção de avaliação, para o desligamento institucional, passa a ser dividida entre atores interessados na construção da dignidade destes sujeitos e na alteração da realidade e do quadro de criminalidade numa perspectiva democrática de convívio social (CAPITÃO, 2008, p. 184).

A contribuição recente das referências da Justiça Restaurativa no cenário brasileiro traz possibilidades de respostas socioeducativas, para as necessidades abstraídas e subjacentes às violências, que reclamam a intervenção do Estado e da sociedade civil (BRANCHER; AGUINSKY, 2006b). Reconhecendo que velhos e persistentes dilemas atravessam o campo da socioeducação, talvez as novas referências e novas abordagens representadas pela Justiça Restaurativa carreguem o signo da esperança de que, neste novo milênio, anuncie-se a possibilidade de democratização do atendimento à juventude em conflito com a lei e a de redução das violências praticadas pelo Estado, em resposta aos crimes perpetrados por adolescentes.

\section{Considerações finais}

A Justiça Restaurativa no Sistema de Justiça da Infância e Juventude implica uma mudança de ótica e uma nova ética na significação das violências em relação às situações levadas à jurisdição da execução das medidas socioeducativas. Essas passam a ser tomadas como necessidades não atendidas de todos os afetados por ofensa, delito, conflito, violência. Essa clivagem altera o foco da abordagem que passa da busca de culpados e da mera punição para a construção de reconhecimento social de todos os envolvidos e de proposições compartilhadas de reparação, superação e prevenção dos danos. Assim, as responsabilidades que são desenhadas nesse processo passam a fazer sentido para todos: ofensores, vítimas, para a rede primária e secundária de ambos, e também para a comunidade.

Em sua pesquisa, recentemente realizada na FASE/RS, sobre iniciativas de Justiça Restaurativa no âmbito da privação de liberdade, Capitão (2008) encontrou uma significativa contribuição da mesma, relacionada a princípios éticos. Essas iniciativas dizem respeito a valores como o respeito, a horizontalidade, a participação, o protagonismo, a inclusão, e às suas repercussões na democratização da política de atendimento socioeducativo. Procuram enfrentar as expressões de naturalização da reprodução das violências, que se manifestam no modo e condição de vida dos adolescentes autores de ato infracional e, inclusive, nas práticas institucionais.

A Justiça Restaurativa abre novas possibilidades para a construção de responsabilidade genuína, no seio da experiência de interação com a força coercitiva do Estado. Numa perspectiva de redução de dano destas intervenções, busca minimizar a violência de práticas institucionais e profissionais no seu âmbito de atuação. Esse novo paradigma de justiça, ao invés de competir com os procedimentos usuais, adotados pela justiça convencional, dá a eles um sentido novo, baseado na participação, autonomia, inclusão (MARSHALL; BOYACK; BOWEN, 2005). Sua introdução nos programas de atendimento da privação de liberdade pode contribuir para a responsabilidade ativa de todos os envolvidos na busca de alternativas para enfrentar a realidade de vio- 
lências; concorrendo também para a concepção de significados ético-pedagógicos, nas práticas usuais da socioeducação.

\section{Referências}

BRANCHER, L.; AGUINSKY, B. Juventude, crime \& justiça: uma promessa impagável. In: ILANUD; ABMP; SEDH; UNFPA. (Org.). Justiça, adolescente e ato infracional. São Paulo: Ilanud, 2006a.

. Histórico de implementação do projeto Justiça para o Século 21. 2006b. Disponível em: <http://www. justica21.org.br/j21/interno.php?ativo=BIBLIOTECA $\&$ sub_ativo $=$ RESUMO\&artigo $=241>$. Acesso em: $20 \mathrm{abr}$. 2008.

CALDEIRA, T. P. do R. Cidade de muros: crime, segregação e cidadania em São Paulo. São Paulo: Editora 34,2008

CAPITÃO, L. C. D. Sócio-educação em xeque: interfaces entre a Justiça Restaurativa e o atendimento a adolescentes privados de liberdade. 2008, Dissertação (Mestrado em Serviço Social) - Programa de Pós-Graduação da Faculdade de Serviço Social. Pontifícia Universidade Católica do Rio Grande do Sul (PUCRS). Porto Alegre, 2008.

MARSHALL, C.; BOYACK, J.; BOWEN, H. Como a Justiça Restaurativa assegura a boa prática: uma abordagem baseada em Valores. In: SLAKMON, C. R.; De VITTO, R. C. P.; PINTO, R. S. G. (Org.). Justiça Restaurativa. BrasíliaDF: Ministério da Justiça e Programa das Nações Unidas para o Desenvolvimento, 2005.

McCOULD, P.; WACHTEL, T. Em busca de um paradigma: uma teoria de Justiça Restaurativa. In: XIII CONGRESSO MUNDIAL DE CRIMINOLOGIA XIII. Rio de Janeiro, ago. 2003. Disponível em: <http://restorativepractices.org/ library/paradigm_port.html>. Acesso em: 18 maio 2007.

MENDEZ, E. G. Adolescentes e responsabilidade penal: um debate latino-americano. Porto Alegre, 2001. Disponível em: <http://www.abmp.org.br/textos/2533.htm>. Acesso em: 20 abr. 2008.

ONU. Princípios básicos para utilização de programas de justiça restaurativa em matéria criminal. Resolução 2002/12. Versão portuguesa produzida por Renato Sócrates Pinto. Disponível em: <http://www.idcb.org.br>. Acesso em: 12 jan. 2008.

SCHMIDT, F. Adolescentes privados de liberdade: a dialética dos direitos conquistados e violados. 2007. Dissertação (Mestrado em Serviço Social) - Programa de Pós-Graduação da Faculdade de Serviço Social, Pontifícia
Universidade Católica do Rio Grande do Sul (PUCRS), Porto Alegre, 2007.

SINASE-Sistema Nacional de Atendimento SócioEducativo, Secretaria Especial dos Direitos Humanos. Brasília: Conanda, 2006.

TEJADAS, S. Juventude e ato infracional: as múltiplas determinações da reincidência. 2005. Dissertação (Mestrado em Serviço Social) - Programa de Pós-Graduação da Faculdade de Serviço Social, Pontifícia Universidade Católica do Rio Grande do Sul (PUCRS), Porto Alegre, 2005.

WACQUANT, L. As prisões da miséria. Tradução de André Telles. Rio de Janeiro: Jorge Zahar, 2001.

ZAFFARONI, E. R. et al. Direito Penal Brasileiro. Rio de Janeiro: Revan, 2003. (v. 1).

\section{Notas}

1 Documento-guia na implementação das medidas socio educativas. Objetiva primordialmente o desenvolvimento de uma ação socio educativa, sustentada nos princípios dos direitos humanos; defende, ainda, a idéia dos alinhamentos conceitual, estratégico e operacional, estruturada, principalmente, em bases éticas epedagógicas(SINASE, 2006,p. 16).

2 Prazo máximo de cumprimento de internação provisória, conforme dados da unidade de internação provisória da Fundação de Atendimento Sócio-Educativo do Rio Grande do Sul(FASE/RS. Disponível em: http://www.fase.rs.gov.br/ portal/index.php). Dados fornecidos pela Assessoria de Informação e Gestão em 18 de abril de 2008.

\section{Beatriz Aguinsky}

Doutora em Serviço Social pela Faculdade de Serviço Social da PUCRS

Coordenadora do Programa de Pós-Graduação da Faculdade de Serviço Social da PUCRS

Assistente social do Poder Judiciário do estado do Rio Grande do Sul

\section{Lúcia Capitão}

Mestre em Serviço Social pela Faculdade de Serviço Social da PUCRS

Assistente Social da Fundação de Atendimento Sócio-Educativo do Estado do Rio Grande do Sul

\section{PUCRS}

Programa de Pós-Graduação em Serviço Social Av. Ipiranga, 6681

Prédio 15 - 3. andar - sala 330

Porto Alegre - Rio Grande do Sul

CEP: 90619-900 